\title{
Clinical evaluation of viral acute respiratory tract infections in children presenting to the emergency department of a tertiary referral hospital in the Netherlands
}

Jairo Gooskens ${ }^{1 *}$, Vishnu van der Ploeg ${ }^{1}$, Ram N Sukhai ${ }^{2}$, Ann CTM Vossen ${ }^{1}$, Eric CJ Claas ${ }^{1}$ and Aloys CM Kroes ${ }^{1}$

\begin{abstract}
Background: The relative incidence and clinical impact of individual respiratory viruses remains unclear among children presenting to the hospital emergency department with acute respiratory tract infection (ARTI).

Methods: During two winter periods, respiratory virus real-time multiplex PCR results were evaluated from children ( $<18$ years) presenting to the emergency department of a tertiary referral hospital with ARTI that had been sampled within 48 hours of hospital presentation. In an attempt to identify virus-specific distinguishing clinical features, single virus infections were correlated with presenting signs and symptoms, clinical findings and outcomes using multivariate logistic regression.

Results: In total, 274 children with ARTI were evaluated and most were aged $<3$ years $(236 / 274,86 \%)$. PCR detected respiratory viruses in 224/274 (81.8\%) children and included 162 (59\%) single and 62 (23\%) mixed virus infections. Respiratory syncytial virus (RSV) and human rhinovirus (HRV) single virus infections were common among children aged < 3 years, but proportional differences compared to older children were only significant for RSV ( $95 \% \mathrm{Cl} 1.315)$. Clinical differentiation between viral ARTls was not possible due to common shared presenting signs and symptoms and the high frequency of mixed viral infections. We observed virus-associated outcome differences among children aged $<3$ years. Oxygen treatment was associated with RSV (OR 3.6) and inversely correlated with FLU (OR 0.05).

Treatment with steroids (OR 3.4) or bronchodilators (OR 3.4) was associated with HRV. Severe respiratory complications were associated with HRV (OR 3.5) and inversely correlated with RSV (OR 0.24).

Conclusions: Respiratory viruses are frequently detected in young children presenting to the hospital emergency department with ARTI and require PCR diagnosis since presenting signs and symptoms are not discriminant for a type of virus. RSV and HRV bear a high burden of morbidity in the pediatric clinical setting.
\end{abstract}

Keywords: Acute respiratory tract infection, Pediatric emergency department, Respiratory virus, Signs and symptoms, Clinical outcome

\footnotetext{
* Correspondence: j.gooskens@lumc.nl

${ }^{1}$ Department of Medical Microbiology, Leiden University Medical Center, Leiden, The Netherlands

Full list of author information is available at the end of the article
}

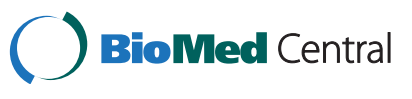

2014 Gooskens et al.; licensee BioMed Central Ltd. This is an Open Access article distributed under the terms of the Creative Commons Attribution License (http://creativecommons.org/licenses/by/4.0), which permits unrestricted use, distribution, and reproduction in any medium, provided the original work is properly credited. The Creative Commons Public Domain Dedication waiver (http://creativecommons.org/publicdomain/zero/1.0/) applies to the data made available in this article, unless otherwise stated. 


\section{Background}

Children suffer through multiple episodes of viral acute respiratory tract infection (ARTI) annually and symptoms range from common mild upper respiratory illness to lower respiratory tract infection (LRTI) [1,2]. Large-scale studies during the past decades were unable to provide accurate virus-specific clinical correlations due to the low sensitivity of viral culture and immunofluorescence techniques and inability of these diagnostic methods to detect non-culturable or mixed viral infections $[1,3]$. The routine implementation of multiplex PCR in recent years has allowed for sensitive and accurate identification of single and mixed viral infections. [4,5].

The burden of individual respiratory viruses remains unclear among different pediatric age-groups in the clinical setting. Recent molecular population-based studies show that viral ARTIs exceed $21 \%$ of pediatric emergency department visits during the seasonal influenza winter season and annual hospitalization rates exceed 1.5 per 100 children aged $<3$ years [6-8]. These findings suggest a high burden of viral ARTI in young children. The burden of viral respiratory pathogens in children is underestimated since human rhinovirus (HRV) infections were not evaluated in these studies. Recent clinical studies have included HRV molecular diagnostics, but interpretation of virusassociated correlations is hampered by age- and symptomrelated enrollment differences $[9,10]$ or by sampling during the 2009 influenza pandemic [11,12].

This study assessed the relative incidence of respiratory virus infections in children presenting to the emergency department of a tertiary hospital with ARTI during two winter seasons and evaluated virus-specific clinical correlations in young children.

\section{Methods}

\section{Study design and patient populations}

This retrospective cohort study included all children aged $<18$ years presenting to the emergency department of Leiden University Medical Center (LUMC) during the 2006 and 2007 winter seasons (November-April) with ARTI who were sampled within 48 hours of hospital presentation. The LUMC is a tertiary referral hospital for the south-western part of the Netherlands covering a population of approximately 2 million inhabitants. Clinical diagnosis of ARTI was made by the attending physician. Routine diagnostic specimens were prospectively analysed by respiratory virus multiplex PCR to evaluate the relative incidence of respiratory viruses among different pediatric age-groups (children aged $<3$ years and children aged 317 years). Structured medical records of children aged $<3$ years with single virus infections (RSV, HRV, FLU or Other) were evaluated for baseline characteristics, presenting signs and symptoms and clinical outcomes.

\section{Respiratory specimens and molecular diagnostics}

Qualified medical personnel obtained diagnostic respiratory specimens and a single specimen was evaluated for each child sampled within 48 hours of hospital presentation. Respiratory specimens included nasopharyngeal washes, throat swabs, nasal swabs, sputum or tracheal aspirates. Nucleic acid was extracted by using a MagnaPure LC total nucleic acid kit (Roche Diagnostics, Mannheim, Germany) as described [4]. A fixed amount of equine arteritis virus served as an RNA internal control and phocid herpesvirus was used as a DNA internal control. Respiratory virus multiplex PCR detected respiratory syncytial virus (RSV), human rhinovirus (HRV), influenzavirus (FLU) A/B, parainfluenzavirus (PIV) 1/2/3/ 4, human metapneumovirus (HMPV), human coronavirus (HCoV) 229E/NL63/OC43, and adenovirus (HAdV) in multiple tubes as described [4]. Primers, probes and amplification methods of the multiplex PCR used in this study are described in reference 4 for laboratory 2 . In a pilot run during the 2007 winter season, we performed additional real-time PCR analysis of $\mathrm{HCoV} \mathrm{HKU1}$, Mycoplasma pneumoniae and Chlamydophila pneumoniae [4]. During this pilot run, we performed additional analysis of human bocavirus $(\mathrm{HBoV})$ by real-time PCR amplification of a 138-bp fragment of the NS1 gene as described by others [13].

\section{Ethics}

The study was conducted in accordance with ethical principles expressed in the World Medical Associations Declaration of Helsinki. The study procedures complied with legal and regulatory standards and clinical data was obtained by following professional codes of conduct. All necessary precautions were taken to prevent identification of any child included in the study. The Medical Ethics Committee (MEC) of Leiden University Medical Center reviewed the study protocol (C14.128) and final version of the manuscript and confirms that the study is based on clinical data collected in the context of routine clinical practice. For this retrospective analysis of routine clinical data the committee declares that no formal ethical approval and written informed consent is needed.

\section{Study procedure \\ Viral distribution}

Routine diagnostic PCR results from all eligible children were analysed. Distribution of RSV, HRV, FLU and Other single virus infections was depicted by age-groups (young children aged $<3$ years and children aged 317 years). PIV, HMPV, HAdV and $\mathrm{HCoV}$ were aggregated into a distinct group (Other) due to small numbers and to enable more accurate comparative virus-associated correlations. 


\section{Presenting signs and symptoms}

The attending physician recorded signs and symptoms of young children aged $<3$ years using structured medical records. Presenting signs and symptoms manifesting within 48 hours of hospital presentation of children with RSV, HRV, FLU or Other single virus infections were evaluated. Virus-associated symptoms were compared and included fever $>38.5 \mathrm{C}$, cough, rhinitis, pharyngitis, wheezing, crepitations, dyspnea or tachypnea. The clinical presence of chest wall retractions, nasal flaring, moaning or laboured breathing were used to define dyspnea. World Health Organization clinical diagnostic criteria defined tachypnea among children aged $<2$ months ( $\geq 60$ breaths per minute, bpm), aged 2 to 12 months ( $\geq 50 \mathrm{bpm})$ and aged $\geq 12$ months $(\geq 40 \mathrm{bpm})$.

\section{Outcomes}

The attending physician recorded outcomes of children aged $<3$ years with RSV, HRV, FLU and Other single virus infections. We evaluated laboratory and pulmonary imaging findings that were obtained within 96 hours of hospital presentation and adverse outcome manifestations (hospital admission, severe respiratory complications, mortality) that were recorded within $\leq 7$ days of hospital presentation. Laboratory findings included C-reactive protein (CRP) and white blood cell count (WBC). We evaluated cut-offs that would indicate absence of serious bacterial infections $\left(\mathrm{CRP}<35 \mathrm{mg} / \mathrm{l} ; \mathrm{WBC}<15 \times 10^{9} / \mathrm{L}\right) \quad[14,15]$. We compared bacteriology results that were obtained by PCR (atypical bacteria) or from routine cultures from non-sterile (urine, sputum) and sterile sites (blood, cerebrospinal fluid). Pulmonary imaging findings were assessed for signs of LRTI (radiologic presence of alveolar or peribronchial infiltrates, interstitial opacities, hyperinflation). Supplemental treatments included brochodilators, steroids, oxygen supplementation and antibiotics. Oxygen supplementation was provided during sustained oxygen saturation $\leq 92 \%$ or during dyspnea with abnormal PCO2 levels. Adverse outcomes included hospital admission, development of severe respiratory complications and all-cause mortality $\leq 7$ days of hospital presentation. Severe respiratory complications were defined as apnea, respiratory intubation and Apparent Life Threatening Events (ALTE). ALTE was defined as an acute change in an infants breathing behavior perceived as possibly life threatening by the childs caretaker.

\section{Statistical analysis}

Statistical analyses were performed using SPSS software version 20.0 (SPSS, Chicago, IL). Continuous variables were presented as mean or median (with range) and categorical variables as frequencies (with percentages). Mann Whitney U-test and Kruskal Wallis test were used as non-parametric tests to compare age (months) between 2 or more groups, because of non-normally distributed data. Chi square was performed to compare categorical variables between 2 groups. Logistic regression analysis compared categorical variables between virus groups including presenting signs and symptoms, diagnostic, treatment and outcome findings. Multivariate analyses adjusted for age, gender and relevant history or chronic underlying disorders (stepwise). A 2-sided value of $P<0.05$ was considered significant.

\section{Results}

\section{Patient enrollment and viral etiology}

During two winter seasons, we enrolled 274 children presenting to the emergency department with ARTI and sampled within 48 hours of hospital presentation. The majority of children were aged $<3$ years $(236 / 274,86 \%)$ compared to older children aged 317 years (38/274, $14 \%)$. Multiplex PCR detected respiratory viruses in $82 \%$ $(224 / 274)$ of all children and included single virus infections (162 of 224, 72\%) and mixed viral infections (62 of 224, 28\%) (Figure 1). Single virus infections were caused by RSV (69 of 224, 31\%), HRV (53 of 224, 24\%), FLU (16 of $224,7 \%)$ and Other (24 of 224, 11\%). In a pilot run among a total 131 children during the 2007 winter season, PCR yielded HBoV (7\%) and HCoV HKU1 (1\%), but no Mycoplasma pneumoniae and Chlamydophila pneumoniae. HBoV- and $\mathrm{HCoV} \mathrm{HKU} 1$-associated clinical findings were not evaluated due to a rare occurrence of single virus infections $(n=4 \mathrm{HBoV} ; n=0 \mathrm{HCoV}$ HKU1) and due to incomplete data (single season).

\section{Respiratory virus distribution}

The distribution of single virus infections among different age groups was evaluated in an attempt to establish virusassociated clinical correlations. Mixed viral infections were

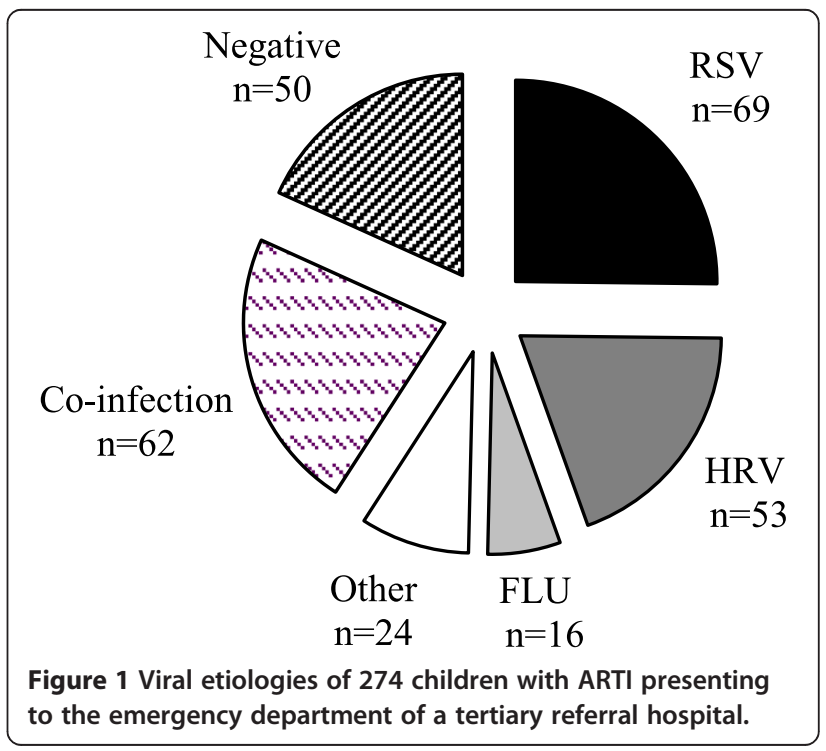


not analyzed due to the small sample size and the difficulty to establish clinical relevance. Single virus infections were common among young children aged $<3$ years $(144$ of $236,61 \%$ ) compared to older children (18 of $38,47 \%$ ) but these proportional differences were not statistically significant (Figure 2). RSV and HRV were more common among children aged $<3$ years compared to older children, but proportional differences were only significant for RSV ( $28 \%$ vs $7.9 \%$; $95 \%$ CI 1.3 15). In contrast, young children were less common infected with Other single viruses (including PIV, HMPV, HAdV or HCoV) compared to older children ( $7.2 \%$ vs $18 \%$; $95 \%$ CI 0.130 .90$)$. FLU single virus infections were uncommon in both age groups with a similar low prevalence (range, 5 to $11 \%$ ).

\section{Virus-specific clinical correlations Baseline characteristics}

Evaluation of baseline characteristics was limited to children aged $<3$ years with single virus infections (RSV, HRV, FLU, Other ) with clinical data available. We included demographics (sex, age) and relevant history encompassing prematurity at birth (gestational age $<37$ weeks), bronchial hyperreactivity (bronchoconstriction in response to stimuli) and underlying pulmonary, cardiovascular and immunodeficiency disorders. Base-line characteristics were equally distributed among virus groups, except for a male predominance (Table 1) among children with HRV vs FLU (73\% vs 36\%; $95 \%$ CI 1.2 19). Proportional differences at baseline underscore the need for statistical adjustment for possible confounders during comparative analyses.

\section{Signs and symptoms}

Presenting signs and symptoms were compared among 138 children aged $<3$ years with single virus infections and clinical data available (Table 1, Figure 3). Six children were previously excluded from comparative analyses due to incomplete documentation. Children aged 317 years were not evaluated due to small numbers and age-related confounding differences. Multivariate analyses adjusted for possible confounders including age and sex, and stepwise for relevant underlying disorders. Significant virusassociated presenting signs and symptoms (Figure 3) included fever (FLU vs RSV, $P=0.01$; FLU vs HRV, $P=$ 0.01 ), cough (RSV vs FLU, $P=0.02$; RSV vs Other, $P=$ 0.03 ), crepitations (RSV vs HRV, $P=0.02$ ), dyspnea and tachypnea (RSV vs FLU, $P=0.04$ ).

\section{Clinical outcomes}

Clinical outcomes were compared among 123 children aged $<3$ years with single virus infections and clinical data available (Table 1, Table 2). A total of 21 children were previously excluded from comparative analyses due to incomplete documentation or hospital transfer without follow-up data. Excluded cases were equally distributed among virus groups (Table 1). High levels of CRP $(\geq 35 \mathrm{mg} / \mathrm{l})$ or WBC $\left(\geq 15 \times 10^{9} / \mathrm{L}\right)$ and antibiotic treatment were equally distributed among virus groups and suggested no differences in potential serious bacterial infections. Bacterial cultures and PCRs were often negative and were equally distributed among individual virus infections. This supports the assumption that there were no differences in potential serious bacterial infections among virus groups. Hospital admission $(\sim 80 \%)$ was equally distributed and fortunately there was no mortality. Overall and individual comparisons were made among children with RSV, HRV, FLU and Other single virus infections (Table 2) following multivariate adjustment for possible confounders.

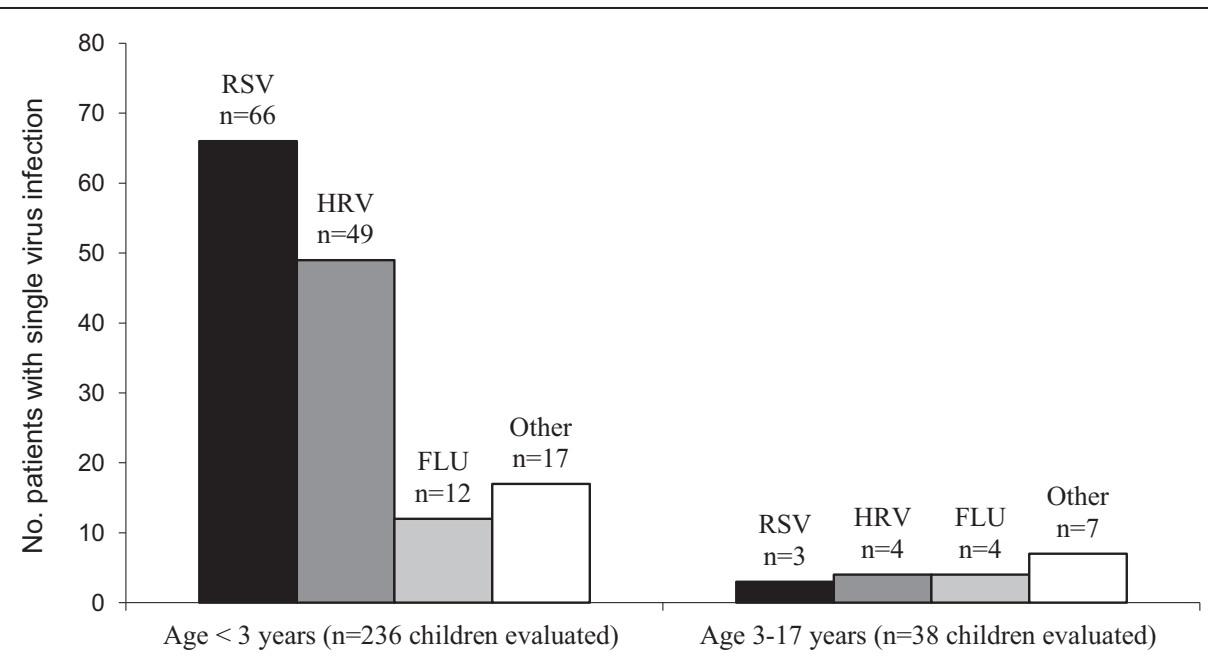

Figure 2 Distribution of single respiratory virus infections among different pediatric age groups. 
Table 1 Baseline characteristics of children aged $<3$ years with single respiratory virus infections

\begin{tabular}{|c|c|c|c|c|c|}
\hline & Total & RSV & HRV & FLU & Other \\
\hline & N (\%) & $\mathrm{N}(\%)$ & $\mathrm{N}(\%)$ & N (\%) & N (\%) \\
\hline \multicolumn{6}{|l|}{ Children $<3$ y with single virus ARTI } \\
\hline Total included & 144 & 66 & 49 & 12 & 17 \\
\hline Analysis of signs and symptoms (data available) & 138 & 64 & 46 & 11 & 17 \\
\hline Analysis of clinical outcomes (data available) & 123 & 53 & 44 & 11 & 15 \\
\hline \multicolumn{6}{|l|}{ Demographics (analysis of clinical outcomes) } \\
\hline Male & $76(62)$ & $30(57)$ & $32(73)^{\$}$ & $4(36)^{5}$ & $10(67)$ \\
\hline Mean age, months [range] & $8\left[\begin{array}{ll}0 & 35\end{array}\right]$ & $7\left[\begin{array}{ll}0 & 35\end{array}\right]$ & $7\left[\begin{array}{ll}0 & 24\end{array}\right]$ & $10\left[\begin{array}{ll}1 & 26\end{array}\right]$ & $11\left[\begin{array}{ll}0 & 33\end{array}\right]$ \\
\hline Median age, months [range] & $4\left[\begin{array}{ll}0 & 35\end{array}\right]$ & $3\left[\begin{array}{ll}0 & 35\end{array}\right]$ & $4\left[\begin{array}{ll}0 & 24\end{array}\right]$ & $9\left[\begin{array}{ll}1 & 26\end{array}\right]$ & $8\left[\begin{array}{ll}0 & 33\end{array}\right]$ \\
\hline \multicolumn{6}{|l|}{ Clinical history (analysis of clinical outcomes) } \\
\hline Prematurity at birth & $11(9)$ & $6(11)$ & $3(7)$ & $1(9)$ & $1(7)$ \\
\hline History of BHR & $12(9)$ & $5(9)$ & $5(11)$ & $1(9)$ & $1(7)$ \\
\hline Chronic pulmonary disorder & $2(2)$ & 0 & $2(5)$ & 0 & 0 \\
\hline Chronic cardiovascular disorder & $12(10)$ & $3(6)$ & $6(14)$ & $1(9)$ & $2(13)$ \\
\hline Chronic immunodeficiency disorder & $5(4)$ & 0 & $2(5)$ & $1(9)$ & $2(13)$ \\
\hline
\end{tabular}

Baseline characteristics are equally distributed, except for a male predominance with HRV vs FLU $(95 \% \mathrm{Cl} 1.2-19)^{5}$.

RSV

Overall, RSV infection was associated with supplemental oxygen requirement (OR 3.6) and inversely correlated with severe respiratory complications (OR 0.24). Individual comparisons revealed that RSV was associated with supplemental oxygen requirement compared to FLU (OR 26) and Other (OR 4.2).

\section{HRV}

Overall, HRV infection was associated with bronchodilator therapy (OR 3.0), steroid treatment (OR 3.4) and severe respiratory complications (OR 3.5). Individual comparisons revealed that HRV was associated with bronchodilator therapy compared to Other (OR 7.0), steroid treatment compared to RSV (OR 3.5), supplemental oxygen requirement

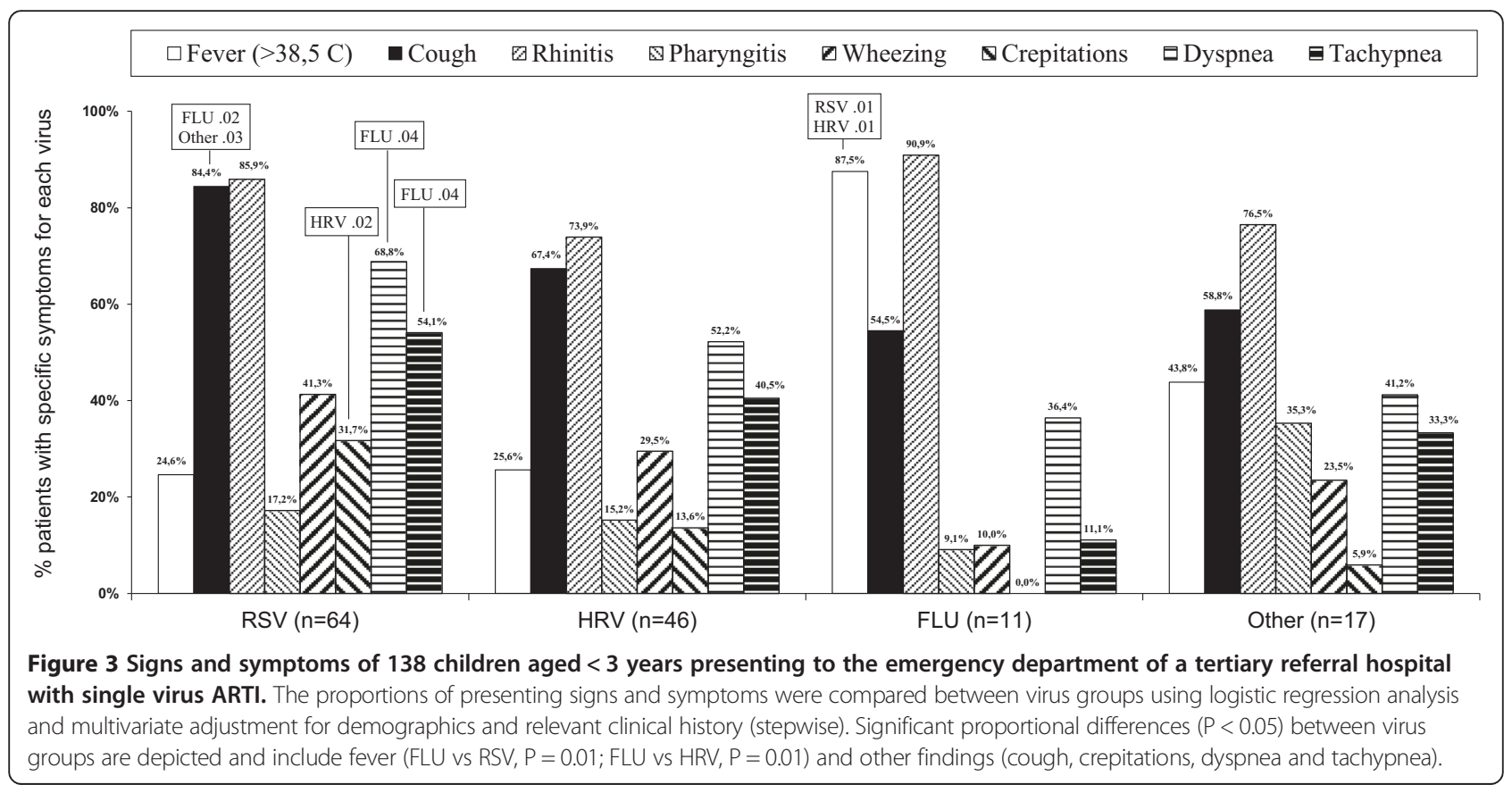


Table 2 Outcomes associated with single respiratory virus infections in children aged $<3$ years

\begin{tabular}{|c|c|c|c|c|c|c|c|c|}
\hline & \multicolumn{5}{|c|}{ Single virus ARTI } & \multicolumn{3}{|c|}{ Statistical analysis } \\
\hline & Total & RSV & HRV & FLU & Other & vs & Multivariate & $P$ \\
\hline & $\mathrm{N}(\%)$ & N (\%) & N (\%) & $\mathrm{N}(\%)$ & N (\%) & & OR $(95 \% \mathrm{Cl})$ & value \\
\hline \multicolumn{9}{|l|}{ Diagnostics } \\
\hline \multicolumn{9}{|l|}{ Chemistry/hematology } \\
\hline$C R P \geq 35 \mathrm{mg} / \mathrm{L}$ & 28/81 (35) & $11 / 32(34)$ & $11 / 29(38)$ & $2 / 9(22)$ & 4/11 (36) & & & NS \\
\hline$W B C \geq 15 \times 109 / L$ & $27 / 80(34)$ & $11 / 32(34)$ & $11 / 28(39)$ & $2 / 9(22)$ & $3 / 11(27)$ & & & NS \\
\hline \multicolumn{9}{|l|}{ Bacteriology } \\
\hline PCR atypical bacteria & 0/10 (0) & $0 / 2(0)$ & 0/4 (0) & $0 / 1(0)$ & $0 / 3(0)$ & & & NS \\
\hline Culture, sterile site & $2 / 45(4)$ & $0 / 15(0)$ & $1 / 17(6)$ & $0 / 7(0)$ & $1 / 6(17)$ & & & NS \\
\hline Culture, non-sterile site & $1 / 19(5)$ & $0 / 7(0)$ & $0 / 8(0)$ & $0 / 1(0)$ & 1/3 (33) & & & NS \\
\hline \multicolumn{9}{|l|}{ Pulmonary imaging } \\
\hline LRTI $^{\#}$ & $31 / 63(37)$ & $15 / 24(63)$ & $10 / 25(40)$ & 3/6 (33) & 3/8 (38) & & & NS \\
\hline \multicolumn{9}{|l|}{ Treatment } \\
\hline Antibiotics & $50 / 122(41)$ & $24 / 53(45)$ & $17 / 43(40)$ & $3 / 11(27)$ & $6 / 15(40)$ & & & NS \\
\hline \multirow[t]{2}{*}{ Bronchodilators } & $31 / 113(27)$ & $12 / 48(25)$ & 15/39 (38) & 2/11 (18) & 2/15 (13) & HRV vs Other & $7.0(1.2-42)$ & .03 \\
\hline & & & & & & HRV overall & $3.0(1.2-7.8)$ & .02 \\
\hline \multirow[t]{2}{*}{ Steroids } & 26/117 (22) & $8 / 52(15)$ & 13/39 (33) & 2/11 (18) & $3 / 15(20)$ & HRV vs RSV & $3.5(1.2-11)$ & .03 \\
\hline & & & & & & HRV overall & $3.4(1.2-9.3)$ & .02 \\
\hline \multirow[t]{5}{*}{ Oxygen therapy } & $67 / 118(57)$ & $38 / 52(73)$ & $22 / 41(54)$ & $1 / 10(10)$ & $6 / 15(40)$ & RSV vs FLU & $26(3.0-225)$ & $<.01$ \\
\hline & & & & & & RSV vs Other & $4.2(1.3-14)$ & .02 \\
\hline & & & & & & HRV vs FLU & $11(1.2-97)$ & .03 \\
\hline & & & & & & RSV overall & $3.6(1.6-8.0)$ & $<.01$ \\
\hline & & & & & & FLU overall & $.05(.01-.40)$ & $<.01$ \\
\hline \multicolumn{9}{|l|}{ Adverse outcome } \\
\hline Hospital admission & $99 / 123(80)$ & $46 / 53(87)$ & $33 / 44(75)$ & $8 / 11(73)$ & $12 / 15(80)$ & & & NS \\
\hline \multirow[t]{3}{*}{ Severe respiratory complication } & 15/123 (12) & $3 / 53(6)$ & $9 / 44(20)$ & $1 / 11(9)$ & 2/15 (13) & HRV vs RSV & $5.0(1.2-21)$ & .03 \\
\hline & & & & & & HRV overall & $3.5(1.0-11)$ & .04 \\
\hline & & & & & & RSV overall & $.24(.06-.92)$ & .04 \\
\hline Apnea & $5 / 123(4)$ & $1 / 53(2)$ & $4 / 44(9)$ & $0 / 11(0)$ & 0/15 (0) & & & NS \\
\hline Intubation & $7 / 123(6)$ & $1 / 53(2)$ & $5 / 44(11)$ & $0 / 11(0)$ & $1 / 15(7)$ & & & NS \\
\hline ALTE & $6 / 123(5)$ & $1 / 53(2)$ & $3 / 44(7)$ & 1/11 (9) & $1 / 15(7)$ & & & NS \\
\hline Mortality $\leq 7$ days & 0/123 (0) & $0 / 53(0)$ & $0 / 44(0)$ & $0 / 11(0)$ & 0/15 (0) & & & NS \\
\hline
\end{tabular}

ARTI, Acute Respiratory Tract Infection, CRP, C-reactive protein; WBC, White Blood Cell count; LRTI, lower respiratory tract infection; ALTE, Apparent Life Threatening Events; NS, not significant.

\#LRTI was defined as radiologic presence of alveolar infiltrates, interstitial opacities, peribronchial infiltrates or hyperinflation.

${ }^{5}$ Multivariate correction for sex, age and underlying disease (forward stepwise adjustment) using logistic regression analysis.

compared to FLU (OR 11) and severe respiratory complications (apnea, respiratory intubation or ALTE) compared to RSV (OR 5.0). HRV subtyping was not performed and therefore specific subtypes could not be associated with clinical outcome.

\section{FLU}

Overall, Flu infection was inversely correlated with supplemental oxygen requirement (OR 0.05). Individual comparisons revealed no FLU specific outcome associations.

\section{Discussion}

This study confirmed a frequent viral etiology among $82 \%$ (224 of 274) of children aged $<18$ years presenting to the emergency department of a tertiary hospital with ARTI. These findings add to a growing body of literature on the epidemiology and virus-associated clinical features in the clinical setting [6-12].

The high detection rate of respiratory viruses using multiplex PCR was similar to previously published rates exceeding $80 \%$ in the pediatric clinical setting $[10,11]$. 
Much lower detection rates (range 58\% - 67\%) in a few other studies are likely due to age- and symptom-related enrollment differences or due to sampling during nonwinter seasons $[9,12]$. A high rate of mixed viral infections in this study (23\%) is similar to findings in other studies (range 14\% - 30\%) [9-11].

Children presenting to the hospital emergency department with ARTI and sampled within 48 hours were predominantly aged $<3$ years (236 of $274,86 \%$ ). HRV and RSV single virus infections were common among children aged $<3$ years, but proportional differences compared to older children were only significant for RSV (95\% CI 1.3 15). Previous studies report a similar predominance of RSV among young children in the clinical setting $[7,8,10]$ but reports on HRV age-distribution are mixed [10,16]. FLU cases were often young children $(n=12)$ compared to older children $(n=4)$ but the small numbers and the lack of a population-based design restrict firm epidemiologic conclusions.

Viral ARTI signs and symptoms are widely presumed to be aspecific but confirmation of this assumption is lacking. This study confirmed that viral ARTI presenting signs and symptoms are aspecific by comparative statistical analysis among children aged $<3$ years with single virus infections. Fever was often associated with influenza (FLU vs RSV, $P=0.01$; FLU vs HRV, $P=0.01$ ) and cough was often associated with RSV (RSV vs FLU, $P=$ 0.02 ; RSV vs Other, $P=0.03$ ). Unfortunately, these and other findings were insufficient to differentiate between individual viral ARTIs due to common shared signs and symptoms among viruses and the high frequency of mixed viral infections [9]. A febrile disease with ARTI symptoms was observed among $\geq 25 \%$ of total viruses infections, therefore influenza-like illness required PCR confirmation to establish FLU diagnosis $[17,18]$.

Virus-specific comparative outcome analysis among children aged $<3$ years with single virus infections unveiled clinical outcome similarities (Table 2). Laboratory infection parameters (CRP, WBC), pulmonary imaging LRTI findings and antibiotic use were similar among virus groups. The findings contrast with a previous study which reported high CRP levels, elevated leucocyte counts and frequent antibiotic use during HRV [10]. In this study, children with RSV often received antibiotics (45\%). Previous studies show that rapid confirmation of RSV can limit antibiotic use $[19,20]$, but antibiotic stewardship guided by respiratory virus PCR results may be difficult to implement [21].

Relevant virus-specific outcome differences include supplemental oxygen treatment requirement (RSV), steroid and bronchodilator treatment (HRV) and development of severe respiratory complications (HRV). Supplemental treatments with corticosteroids and bronchodilators were remarkably associated with HRV. There is insufficient evidence on the benefit of corticosteroids or bronchodilators during viral LRTI and most guidelines do not recommend the routine use for cases of RSV LRTI [22]. However, corticosteroids may improve HRV-induced wheezing and bronchodilators may be effective for individual children experiencing LRTI with underlying reactiveairway disease. This may explain why corticosteroids and bronchodilators were more commonly provided to children with HRV. Young children presenting to the hospital emergency department with the combined symptoms of cough, pulmonary crepitation and oxygen-dependent viral LRTI were more likely to be infected with RSV than with other viruses as reported by others [12,23]. With the knowledge that RSV is more often associated with oxygendependent viral LRTI, it would seem counter-intuitive that HRV (and not RSV) is associated with more severe respiratory complications (Table 2). HRV often causes mild symptoms, but the findings of this and other studies suggest that the occurrence of severe HRV respiratory complications may be underestimated $[24,25]$. In this study, FLU infection was inversely correlated with supplemental oxygen treatment compared to other infections as described by others [26]. We emphasize that the low number of FLU cases does not allow for any firm conclusions on this matter. Previous studies suggest that FLU manifestations may be relatively mild among young children presenting to the hospital during seasonal influenza, but rare life-threatening events and severe cases of concomitant bacterial pneumonia do occur [12,27].

\section{Limitations}

Children were evaluated at a tertiary care setting and this possibly limits the validity of virus-specific clinical correlations in other settings. The retrospective design of the study and evaluation of the patients by different attending physicians may have introduced a reporting bias. The inclusion of children sampled within 48 hours of hospital presentation may have introduced a selection bias towards younger patients due to a more cautious clinical and diagnostic approach of parents and paediatricians in that age group [28]. This could explain why the majority of children included in this study were aged $<3$ years $(236 / 274,86 \%)$.

The respiratory specimens were of different types (including nasopharyngeal washes, throat swabs, nasal swabs, sputum or tracheal aspirates) which could have bearing on the sensitivity of the PCR for the various viruses and thus their relative frequency. The number of children with viral ARTI is an underestimation since our multiplex PCR did not detect $\mathrm{HBoV}, \mathrm{HCoV} \mathrm{HKU} 1$, human influenza $\mathrm{C}$ virus and enteroviruses that may cause viral respiratory infections. Molecular differentiation of HRV and enteroviruses is difficult and the HRV assay used in this study cross-reacts with a few enteroviruses that are associated 
with respiratory infections. This variation in HRV types may explain severe HRV infections and emphasizes that future studies should elucidate the specific role of HRV and enteroviruses using molecular subtyping.

In this study, multiple comparisons were performed which can lead to more type I errors (more false positives) since $5 \%$ of the comparisons have uncorrected $\mathrm{P}$ values $<0.05$. Statistical adjustment of confidence intervals (eg Bonferroni corrections) can be applied to reduce incorrect rejection of true null hypotheses and to lower type I errors, but these corrections can increase the type II error (more false negatives) and lead to interpretation errors [29]. In this observational study, no adjustments were made for multiple comparisons in an attempt to find novel virus-specific clinical correlations. This approach is intended for hypothesis generation and not for hypothesis testing. Future prospective studies using improved standardized study protocols are therefore awaited to confirm virus-associated clinical findings and for hypothesis testing.

\section{Conclusions}

This study confirmed that a viral agent is frequently found in young children with ARTI presenting to the pediatric emergency department of a tertiary referral hospital. Molecular diagnostics are required to confirm respiratory virus infections since presenting symptoms could not discriminate between the viruses. RSV and HRV infections bear the highest burden of morbidity in the pediatric clinical setting.

\section{Abbreviations \\ ARTI: Acute respiratory tract infection; BHR: Bronchial hyperresponsiveness; Bpm: Breaths per minute; CRP: C-reactive protein; FLU: Influenzavirus; HAdV: Human adenovirus; HBoV: Human bocavirus; HCoV: Human coronavirus; HMPV: Human metapneumovirus; HRV: Human rhinovirus; LRTI: Lower respiratory tract infection; OR: Odds ratio; PCR: Polymerase chain reaction; PIV: Parainfluenzavirus; RSV: Respiratory syncytial virus; WBC: White blood count.}

\section{Competing interests}

The authors declare that they have no competing interests. There was no financial support.

\section{Authors contributions}

$J G, V P, R S, A V, E C, A K$ conceived the study. JG, AV, AK led the study design process. JG, EC collected the molecular data. JG, VP, RS collected the clinical data. JG, VP performed the statistical analysis. JG made the first draft of the manuscript. All authors read, revised, and approved the final manuscript.

\section{Acknowledgements}

Ron Wolterbeek (Department of Medical Statistics and Bioinformatics) provided valuable statistical advice. We thank Pulak Goswami for language editing support.

\section{Author details}

${ }^{1}$ Department of Medical Microbiology, Leiden University Medical Center, Leiden, The Netherlands. ${ }^{2}$ Department of Pediatrics, Leiden University Medical Center, Leiden, The Netherlands.
Received: 19 June 2014 Accepted: 18 November 2014

Published online: 10 December 2014

\section{References}

1. Monto AS: Studies of the community and family: acute respiratory illness and infection. Epidemiol Rev 1994, 16:351 373.

2. Yorita KL, Holman RC, Sejvar JJ, Steiner CA, Schonberger LB: Infectious disease hospitalizations among infants in the United States. Pediatrics 2008, 121:244 252.

3. Jacobs JW, Peacock DB, Corner BD, Caul EO, Clarke SK: Respiratory syncytial and other viruses associated with respiratory disease in infants. Lancet 1971, 1:871 876.

4. Loens K, van Loon AM, Coenjaerts F, van Aarle Y, Goossens H, Wallace P, Claas EJ, leven M: GRACE Study Group. Performance of different monoand multiplex nucleic acid amplification tests on a multipathogen external quality assessment panel. J Clin Microbiol 2012, 50:977 987.

5. Freymuth F, Vabret A, Cuvillon-Nimal D, Simon S, Dina J, Legrand L, Gouarin S, Petitjean J, Eckart P, Brouard J: Comparison of multiplex PCR assays and conventional techniques for the diagnostic of respiratory virus infections in children admitted to hospital with an acute respiratory illness. J Med Virol 2006, 78:1498 1504.

6. Forster J, Ihorst G, Rieger $\mathrm{CH}$, Stephan V, Frank HD, Gurth H, Berner R, Rohwedder A, Werchau H, Schumacher M, Tsai T, Petersen G: Prospective population-based study of viral lower respiratory tract infections in children under 3 years of age (the PRI.DE study). Eur J Pediatr 2004, 163:709 716.

7. Iwane MK, Edwards KM, Szilagyi PG, Walker FJ, Griffin MR, Weinberg GA, Coulen C, Poehling KA, Shone LP, Balter S, Hall CB, Erdman DD, Wooten K, Schwartz B: New Vaccine Surveillance Network. Population-based surveillance for hospitalizations associated with respiratory syncytial virus, influenza virus, and parainfluenza viruses among young children. Pediatrics 2004, 113:1758 1764.

8. Bourgeois FT, Valim C, Wei JC, MCAdam AJ, Mandl KD: Influenza and other respiratory virus-related emergency department visits among young children. Pediatrics 2006, 118:e1 e8.

9. Cilla G, Oate E, Perez-Yarza EG, Montes M, Vicente D, Perez T: Viruses in community-acquired pneumonia in children aged less than 3 years old: high rate of viral coinfection. J Med Virol 2008, 80:1843 1849.

10. Garca-Garca ML, Calvo C, Pozo F, Villadangos PA, Prez-Brea P, Casas I: Spectrum of respiratory viruses in children with community-acquired pneumonia. Pediatr Infect Dis J 2012, 31:808 813.

11. Laurent C, Dugu AE, Brouard J, Nimal D, Dina J, Parienti JJ, Vabret A: Viral epidemiology and severity of respiratory infections in infants in 2009: a prospective study. Pediatr Infect Dis J 2012, 31:827 831

12. Pierangeli A, Scagnolari C, Selvaggi C, Monteleone K, Verzaro S, Nenna R, Cangiano G, Moretti C, Papoff P, Antonelli G, Midulla F: Virological and clinical characterization of respiratory infections in children attending an emergency department during the first autumn-winter circulation of pandemic A (H1N1) 2009 influenza virus. Clin Microbiol Infect 2012, 18:366 373

13. Allander T, Tammi MT, Eriksson M, Bjerkner A, Tiveljung-Lindell A, Andersson B: Cloning of a human parvovirus by molecular screening of respiratory tract samples. Proc Natl Acad Sci U S A 2005, 102:12891 12896.

14. Pulliam PN, Attia MW, Cronan KM: C-reactive protein in febrile children 1 to 36 months of age with clinically undetectable serious bacterial infection. Pediatrics 2001, 108:1275 1279.

15. Yo CH, Hsieh PS, Lee SH, Wu JY, Chang SS, Tasi KC, Lee CC: Comparison of the test characteristics of procalcitonin to C-reactive protein and leukocytosis for the detection of serious bacterial infections in children presenting with fever without source: a systematic review and meta-analysis. Ann Emerg Med 2012, 60:591 600.

16. Miller EK, Lu X, Erdman DD, Poehling KA, Zhu Y, Griffin MR, Hartert TV, Anderson $L$, Weinberg GA, Hall CB, Iwane MK, Edwards KM: New Vaccine Surveillance Network. Rhinovirus-associated hospitalizations in young children. J Infect Dis 2007, 195:773 781.

17. Wallace LA, Collins TC, Douglas JD, Mclntyre S, Millar J, Carman WF: Virological surveillance of influenza-like illness in the community using PCR and serology. J Clin Virol 2004, 31:40 45.

18. Schnepf N, Resche-Rigon M, Chaillon A, Scemla A, Gras G, Semoun O, Taboulet P, Molina JM, Simon F, Goudeau A, LeGoff J: High burden of non-influenza viruses in influenza-like illness in the early weeks of H1N1v epidemic in France. PLoS One 2011, 6:e23514. 
19. Woo PC, Chiu SS, Seto WH, Peiris M: Cost-effectiveness of rapid diagnosis of viral respiratory tract infections in pediatric patients. J Clin Microbiol 1997, 35:1579 1581.

20. Purcell K, Fergie J: Concurrent serious bacterial infections in 2396 infants and children hospitalized with respiratory syncytial virus lower respiratory tract infections. Arch Pediatr Adolesc Med 2002, 156:322 324

21. Wishaupt JO, Russcher A, Smeets LC, Versteegh FG, Hartwig NG: Clinical impact of RT-PCR for pediatric acute respiratory infections: a controlled clinical trial. Pediatrics 2011, 128:e1113 e1120.

22. Tregoning JS, Schwarze J: Respiratory viral infections in infants: causes, clinical symptoms, virology, and immunology. Clin Microbiol Rev 2010, 23:74 98.

23. Hall CB, Weinberg GA, Iwane MK, Blumkin AK, Edwards KM, Staat MA, Auinger P, Griffin MR, Poehling KA, Erdman D, Grijalva CG, Zhu Y, Szilagyi P: The burden of respiratory syncytial virus infection in young children. N Engl J Med 2009, 360:588 598.

24. Iwane MK, Prill MM, Lu X, Miller EK, Edwards KM, Hall CB, Griffin MR, Staat MA, Anderson LJ, Williams JV, Weinberg GA, Ali A, Szilagyi PG, Zhu Y, Erdman DD: Human rhinovirus species associated with hospitalizations for acute respiratory illness in young US children. J Infect Dis 2011, 204:1702 1710.

25. Asner SA, Petrich A, Hamid JS, Mertz D, Richardson SE, Smieja M: Clinical severity of rhinovirus/enterovirus compared to other respiratory viruses in children. Influenza Other Respir Viruses 2014, 8:436 442

26. Hite LK, Glezen WP, Demmler GJ, Munoz FM: Medically attended paediatric influenza during the resurgence of the Victoria lineage of influenza B virus. Int J Infect Dis 2007, 11:40 47.

27. Ruf $B R$, Knuf $M$ : The burden of seasonal and pandemic influenza in infants and children. Eur J Pediatr 2014, 173:265 276.

28. Gasparini R, Durando P, Ansaldi F, Sticchi L, Banfi F, Amicizia D, Panatto D, Esposito S, Principi N, Icardi G, Crovari P: Influenza and respiratory syncytial virus in infants and children: relationship with attendance at a paediatric emergency unit and characteristics of the circulating strains. Eur J Clin Microbiol Infect Dis 2007, 26:619 628.

29. Rothman KJ: No adjustments are needed for multiple comparisons. Epidemiology 1990, 1:43 46

doi:10.1186/s12887-014-0297-0

Cite this article as: Gooskens et al: Clinical evaluation of viral acute respiratory tract infections in children presenting to the emergency department of a tertiary referral hospital in the Netherlands. BMC

Pediatrics 2014 14:297.

\section{Submit your next manuscript to BioMed Central and take full advantage of:}

$凶$ Convenient online submission

$\otimes$ Thorough peer review

$\otimes$ No space constraints or color $\nabla$ gure charges

$\otimes$ Immediate publication on acceptance

\Inclusion in PubMed, CAS, Scopus and Google Scholar

$\otimes$ Research which is freely available for redistribution 